\title{
Arqueología de la Arqueología: ensayos sobre los orígenes de la disciplina en México
}

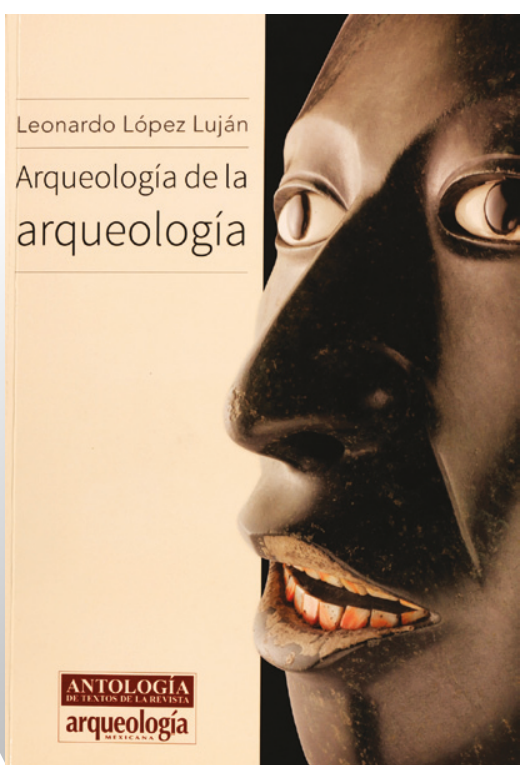

FICHA BIBLIOGRÁFICA

LeOnardo lópez luján, Arqueología de la Arqueología: ensayos sobre los orígenes de la disciplina en México, Instituto Nacional de Antropología e Historia / Editorial Raíces, 2017, 335 págs. ISBN: 978-607-484-986-8

\section{Jorge Maier Allende Real Academia de Bellas Artes de San Fernando}

México o, Mejor dicho, Mesoamérica ocupa un lugar privilegiado en la definición e institucionalización de la Arqueología contemporánea como disciplina científica. En efecto, fue en México donde la Arqueología alcanzó una dimensión universal como método de investigación histórica. Auspiciado por la política cultural de la Corona española, la Arqueología, que se había forjado principalmente en la investigación y redescubrimiento del 
mundo clásico dio el salto hacia su universalidad como método científico de investigación histórica en México con la expedición promovida por el "rey arqueólogo" Carlos III -responsable también del descubrimiento y excavación de las antiguas ciudades de Pompeya y Herculano- en la ruinas de Palenque y continuada más ampliamente por su hijo, Carlos IV, con la Real Expedición Anticuaria de México en los albores del siglo XIX, iniciativas que se nutrieron además por el proceso emancipador y de posterior construcción nacional mexicano $^{1}$. Paradójicamente Alexander von Humboldt, Lord Kingsborough, Henri Baradére, Charles Farcy, Alexander Lenoir y David Bailie Warden, entre otros, fueron los difusores en Europa de estas expediciones arqueológicas en el primer tercio del siglo XIX. Estos son sin duda hitos claves de la Historia de la Arqueología, ya que desde entonces la disciplina emprendería un nuevo rumbo.

La historiografía de la arqueología mexicana cuenta con una ya larga tradición, especialmente a partir de los años 60, con la aparición de la Nueva Arqueología y el creciente interés por el estudio de la historia e historiografía de la disciplina, a uno y otro lado del Atlántico. De especial importancia fue la conmemoración en los años 90 del 200 aniversario del descubrimiento de dos piezas fundamentales de la arqueología mesoamericana, esto es, la Piedra del Sol y la imagen de la diosa Coatlicue, para el fomento y desarrollo de estos estudios historiográficos ${ }^{2}$. No en vano estos descubrimientos fueron producto de uno de los más esplendorosos periodos fundacionales de la arqueología mexicana. Esta fructífera, como necesaria, línea de investigación ha sido últimamente impulsada por el Prof. Dr. Leonardo López Luján, del Instituto Nacional de Antropología e Historia (INAH), Director del Proyecto Templo Mayor y miembro de número de la Academia Mexicana de la Historia.

La Arqueología de la Arqueología es un valioso compendio fruto de tres lustros de trabajos del Dr. López Luján, dedicados a desentrañar y enriquecer la historia de la Arqueología en México. El libro recoge una selección de veintisiete artículos -pues no están todos los que son ni son todos los que están- de los cuales veintitrés fueron publicados a lo largo de quince años en la revista Arqueología Mexicana, esto es, entre 2001 y 2016, mientras tan sólo cuatro de ellos vieron la luz en otras publicaciones. Gran parte de estos artículos fueron realizados en colaboración distintos investigadores entre los que cabe destacar al Prof. Dr. Alfredo López Austin, al Prof. Dr. Eduardo Matos Motezuma, así como al Prof. Dr. Saburo Sugiyama, al Dr. Francisco Xavier Noguez, a la Profa. Dra. Gabriela Sánchez Reyes, a la Dra. Maria Gaida, a la Dra. Laura Filloy Nadal y a la prehistoriadora francesa y americanista Marie-France Fauvet Berthelot.

La obra se presenta con una clara estructura temática, en la que se pueden distinguir tres bloques, que coinciden básicamente con las tres etapas establecidas ya por Ignacio Ber-

1. M. Almagro-Gorbea y J. Maier Allende (eds.), De Pompeya al Nuevo Mundo: la Corona española y la Arqueología en el siglo XVIII, Madrid, 2012.

2. Especialmente impulsados por el Prof. Dr. Eduardo Matos Motezuma con Breve historia de la Arqueología en México, México, 1992, al que siguieron otros muchos estudios entre los que cabría destacar Las piedras negadas. De la Coatlicue al Templo Mayor, México, 1998, que culmina con la reciente, Arqueología del México antiguo, México, 2010. 
nal en su Historia de la Arqueología en México (1979). Tras un artículo introductorio -uno de los más antiguos de la serie- del que se toma el titulo general de la obra, se encuentra un primer grupo que engloba los tres primeros artículos, que versan sobre la documentación de materiales arqueológicos antiguos en contextos más modernos, que nos hablan del interés y veneración de los antiguos mesoamericanos por la cultura material de sus ancestros, y, aunque lógicamente, no se pueda hablar de un interés "anticuario", este interés o fascinación es equiparable con otras grandes culturas clásicas antiguas.

El segundo bloque de artículos tiene como denominador común la valoración de las fuentes antiguas escritas y de sus posibilidades a través de su adecuada relectura en confrontación permanente con los datos arqueológicos, como es el caso de los artículos dedicados al coatepantli de Tenochtitlan y el códice de Teotenantzin.

El tercer bloque de artículos, el más importante y la columna vertebral del libro, está dedicado, como no podía ser de otra manera, a la arqueología mexicana del Siglo de las Luces. No en vano, es esta época la que se considera en la que se encuentra el verdadero despegue de la disciplina en México y es en la que el Prof. Dr. López Luján ha trabajado más intensa y regularmente y en la que ofrece rigurosos, novedosos y jugosos resultados que documentan detalladamente la trascendental aportación de la arqueología mexicana al devenir de la disciplina.

Muy acertadamente encabeza esta serie de trabajos con el impacto que tuvieron en Nueva España el proyecto arqueológico napolitano promovido por Carlos III, ejemplo de la íntima conexión que subyace a todas las iniciativas posteriores. A continuación, les siguen sendos artículos dedicados a dos de los lugares más emblemáticos de la arqueología ilustrada mexicana: El Tajín y Xochicalco, que se completa con un artículo dedicado a una desconocida dimensión de la expedición de Malaspina de 1791, como fue su visita a las impactantes ruinas de Teotihuacán, a las que curiosamente se les prestó muy escasa atención.

Los hallazgos y documentación de piezas en el centro histórico de ciudad de México, y su conservación y depósito en la Academia de Bellas Artes San Carlos o la Universidad, fue una característica de este periodo. A ellos están dedicados varios artículos sobre la diosa Coatlicue, la Piedra del Sol o la Piedra de Tizoc. De gran importancia también son los artículos, fruto de varios años de investigación, sobre los resultados que ha proporcionado la documentación conservada tanto en Francia como en México sobre estos hallazgos, tanto la perteneciente al Capitán de Dragones Guillermo Dupaix ${ }^{3}$ como al más célebre anticuario de este periodo Antonio León y Gama. Esta es, sin duda, una de las más novedosas aportaciones fruto de la investigación archivística y que documenta asimismo las instrucciones que, sobre la recogida y documentación de antigüedades se habían expedido en varias ocasiones desde la metrópoli, así como su relación con la preparación de la redacción de una Historia del Nuevo Mundo por parte de la Real Academia de la Historia, como

3. Esta documentación fue objeto de una exposición, véase nuestra reseña a El capitán Guillermo Dupaix y su álbum arqueológico de 1794, México, 2013, en Revista de Historiografía 25, 2016, pp. 432-435. 
Cronista Mayor de Indias ${ }^{4}$. Este bloque se cierra con el artículo dedicado a Alexander von Humboldt y el hacha olmeca por él publicada. Como hemos señalado, Humboldt, autorizado a viajar por el continente americano por el rey Carlos IV ${ }^{5}$, fue uno de los difusores de la arqueología mexicana en Europa a través de su obra Vistas de las cordilleras y monumentos de los pueblos indígenas de América ${ }^{6}$.

Hay que señalar que esta profusión de estudios y sus importantes aportaciones, que sin duda enriquecen el panorama de este fructífero periodo de la arqueología mexicana del siglo de las Luces, se completa además con algunas otras contribuciones objeto de concienzudas investigaciones por otros investigadores, en mayor o menor medida. Nos referimos, por ejemplo, a la importantísima expedición a las ruinas de Palenque, que, en palabras de Ignacio Bernal fue "el primer programa arqueológico jamás llevado a cabo en México"7, a figuras como el Padre José Márquez ${ }^{8}$, el académico Juan Bautista Muñoz, figura clave en el desarrollo de la arqueología mexicana, o el tan importante papel que tuvo la Real Academia de San Carlos", la primera Academia fundada en todo el continente americano y, por último, la Real Expedición Anticuaria de México, aunque esta última si ha sido objeto de la atención del Dr. López Luján ${ }^{10}$.

4. En este sentido véase J. Maier Allende, “Carlos III y la Arqueología americana”, Boletín de la Real Academia de la Historia CCXIII, 527-542.

5. M. Á. Puig-Samper y S. Rebok, Sentir y medir: Alexander von Humboldt en España, Madrid, 2007.

6. Sobre Humboldt véase además "Wilhelm y Alexander von Humboldt y la anticuaria hispana de la Ilustración”, en M. Almagro-Gorbea y J. Maier Allende (eds.), De Pompeya al Nuevo Mundo: la Corona Española y la Arqueología en el siglo XVIII, Madrid, 2012, 281-298.

7. I. Bernal, Historia de la Arqueología en México, México, 1979, p. 79. Hace ya tiempo publicada por P. Cabello, Política investigadora en el área maya: descubrimiento de Palenque y las primeras excavaciones de ca'racter científico según documentación de Calderón, Bernasconi, Del Río y otros, Madrid, 1992 y J. Alcina, Arqueólogos o Anticuarios. Historia antigua de la Arqueología en la América española. Barcelona, 1995.

8. El jesuita expulso Pedro José Márquez ha sido objeto de numerosas investigaciones, y de dos tesis doctorales de Delfín Rodríguez (1985) y Juana Gutiérrez Haces (1985), ambas inéditas; aquí destacaremos algunas trabajos relacionados más directamente con la Arqueología: J. Fernández, Pedro José Márquez 1741-1820, sobre lo bello en general y dos monumentos de arquitectura mexicana: Tajín y Xochicalco, México, 1972; J. Gutiérrez Haces, "Los antiguos mexicanos, Vitruvio y el padre Márquez", en VV. AA., Mitos, leyendas e historia en el arte mexicano. IX Coloquio Internacional de Historia del Arte, México, 1988, 177-197, y recientemente, J. Gutiérrez Haces, El padre Pedro José Márquez, un erudito mexicano en la Italia del siglo XVIII, México, 2010; O. Flores Flores (coord.), El clasicismo en la época de Pedro José Márquez (1741-1820): arqueología, filología, historia, música y teoría arquitectónica, México-Madrid, 2104.

9. Centro fundamental en la institucionalización de la arqueología mexicana y fruto de la política cultural de la Corona de España; sobre esta institución véase, por ejemplo, E. Báez Macías, Historia de la Escuela Nacional del Bellas Artes (antigua Academia de San Carlos) 1781-1910, México, 2009.

10. Véase, por ejemplo, J. Maier Allende, "La Real Expedición Anticuaria de México (1805-1808), novedades bibliográficas e historiográficas", Anales del Museo de América XXIV, 2016, 60-70. Recientemente ha aparecido la importante contribución de Isabel Estrada de Gerlero, Guillermo Dupaix: precursor de la historia del arte hispánico, México, 2017. 
El último bloque, compuesto de nueve artículos, está dedicado al siglo XIX a partir de la independencia, a un periodo del más puro sabor romántico, caracterizado por la confusión, la laxitud de las medidas proteccionistas, fruto de la inestabilidad política, que sin duda ha contribuido a fraguar una imagen muy conocida del arqueólogo y la Arqueología en el imaginario popular. Es, no obstante, también el periodo de difusión y conocimiento de la arqueología mexicana y de sus antiguas culturas en el resto del mundo y la creación de uno de los principales y más importantes museos arqueológicos, el Museo Nacional de Antropología de México.

En definitiva, La Arqueología de la Arqueología, es una importante contribución más del Prof. Dr. López Luján, una puesta al día al alcance de todos de la historia de la arqueología mexicana y de su determinante papel en el devenir de la Arqueología como ciencia histórica. 